\title{
A clinical study of modified McIndoe vaginoplasty with split thickness skin graft: a tertiary care experience
}

\author{
Atul K. Gowardhan ${ }^{1}$, Priya M. Bagade ${ }^{2 *}$
}

\begin{abstract}
${ }^{1}$ Department of Plastic Surgery, Mahatma Gandhi Medical College and Hospital, Navi-Mumbai, Maharashtra, India ${ }^{2}$ Department of Obstetrics and Gynecology, Mahatma Gandhi Medical College and Hospital, Navi-Mumbai, Maharashtra, India
\end{abstract}

Received: 25 April 2020

Accepted: 25 May 2020

*Correspondence:

Dr. Priya M. Bagade,

E-mail: priyabagade79@gmail.com

Copyright: (c) the author(s), publisher and licensee Medip Academy. This is an open-access article distributed under the terms of the Creative Commons Attribution Non-Commercial License, which permits unrestricted non-commercial use, distribution, and reproduction in any medium, provided the original work is properly cited.

\begin{abstract}
Background: Mayer-Rokitansky-Kuster-Hauser syndrome (MRKH) is associated with failure of fetal mullerian-duct development that results in congenital deficiency of the upper part of the vagina with a rudimentary-to-absent uterus. These patients have primary amenorrhoea, infertility as well as insufficient sexual gratification. Although conception can be dealt with IVF and surrogacy but at least by doing neovaginal construction by McIndoe vaginoplasty, these patients have acceptable sexual life and intercourse. The main objective of this study was creating a neovagina leading to a satisfactory sexual life.

Methods: Modified McIndoe vaginoplasty with split thickness skin graft, was done in seven patients with MRKH syndrome from 2014-2017 and these patients were followed till 2019. All patients had detailed counselling regarding the surgery, the complications involved and the outcome. Thorough investigations were done in all the patients.

Results: The functional results were satisfactory in all the seven patients. There was no blood transfusion requirement or any serious complication involved. An average vaginal length of 7-9 $\mathrm{cm}$ and vaginal width of 3-4 $\mathrm{cm}$ was achieved. Donor site healing was adequate in all patients with no complications.

Conclusions: Modified McIndoe vaginoplasty, if performed with good surgical skills, is a secure and beneficial way to achieve sexual contentment in patient with vaginal agenesis, with no donor site complications.
\end{abstract}

Keywords: Mullerian agenesis, Neovaginal construction, Sexual satisfaction, Split thickness skin graft

\section{INTRODUCTION}

The embryonic failure of mullerian duct formation results in vaginal agenesis or vaginal aplasia. Congenital absence of vagina was first described by Realdus Columbus in 1559. ${ }^{1}$ In 1829 , the German anatomist and physiologist, August Franz Joseph Karl Mayer further revealed its presence as one of the anomalies seen in stillborn infants with multiple congenital abnormilities. ${ }^{2}$ In 1938, von Rokitansky, reported a condition of absence of vagina with a small bipartite uterus, normal ovaries and in association with abnormalities of other systems-mainly renal and skeletal. ${ }^{3}$ A German gynaecologist Hermann
Kuster also narrated the same pathology in $1910 .^{4}$ Eventually the Swiss gynaecologist, Georges Andre Hauser associated the pathology with the failure of Mullerian duct development in the presence of normal 46XX karyotype. ${ }^{5,6}$ Ultimately the condition has come to be known as the Mayer-Rokitansky-Kuster-Hauser syndrome (MRKH).

The congenital absence of vagina is seen in 1 in 40005000 female births. ${ }^{7,8}$ It is most commonly seen in MRKH syndrome. Mayer-Rokitansky-Kuster-Hauser syndrome i.e. uterovaginal agenesis is characterised by presence of conventional female karyotype and ovaries. ${ }^{9}$ 
Patients have normal endocrine status and are genotypically and phenotypically females. ${ }^{10}$ They have usual secondary sexual character development and female body habitus. Most commonly, the diagnosis is done at puberty or later age due to amenorrhoea or inability to have intercourse. ${ }^{11}$

Various psychological issues and body accentuation problems resulting from sexual displeasure have been noted in these patients. ${ }^{12,13}$ Hence creating a neovagina increases their self-esteem by sexual satisfaction of both the partners. ${ }^{14}$ Different non-operative and operative methods for neovagina construction have been described in the past.

The main purpose of all these procedures have been the creation of a vagina that will be satisfying in the look, functionality and feeling without major morbidity. Vaginal reconstruction was $1^{\text {st }}$ performed by Amussat in 1832. ${ }^{15}$ Non-operative technique involves the use of vaginal dilators for creating a neovagina. However, this involves a highly motivated person who does not want to opt for surgery. ${ }^{16}$

Operative methods include various flap techniques, buccal mucosa grafts, amnion grafts, the bowel loop substitution, peritoneal methods and the skin graft techniques. Amidst all these, modified McIndoe vaginoplasty using split thickness skin graft has been highly accepted technique due to its simplicity and efficacy. ${ }^{17}$ Bainster and McIndoe first described the McIndoe technique using split thickness skin graft in 1938. ${ }^{18,19}$

The purpose of this study was to determine the effectiveness of modified McIndoe vaginoplasty for vaginal reconstruction and patient's sexual satisfaction.

\section{METHODS}

The study was conducted in the department of obstetrics and gynecology, MGM Medical college, Navi Mumbai from 2014-2017. A total of 7 cases of MRKH syndrome who met the criteria for reconstructive surgery underwent modified McIndoe vaginoplasty with split thickness skin graft. All these cases were further followed up till 2019. A detailed history taking and examination of these patients was done. All the routine investigations required for major surgery along with ultrasound, hormone assessment and karyotype was carried out in these patients. A written informed consent was taken from all the patients explaining in detail about the procedure, the possible complications and the results.

\section{Technique}

Preoperatively patients were prepared for the surgery as per the hospital protocols. Gynecologist along with Plastic surgeon performed the surgery under spinal anesthesia. Patients were catheterized preoperatively and prophylactic antibiotic was given before starting the procedure. Surgery was performed with the patient in the lithotomy position.

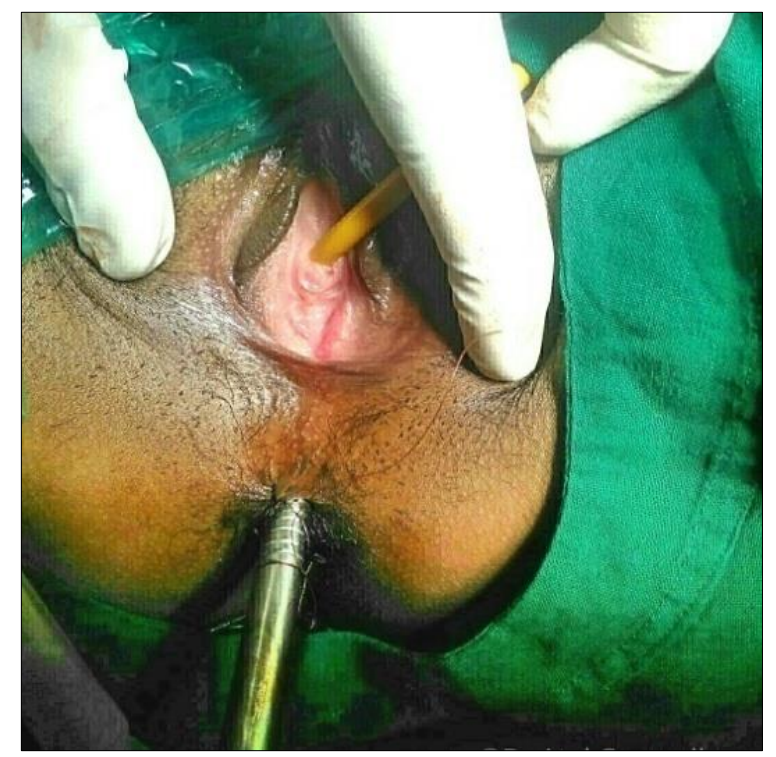

Figure 1: Absence of vagina in MRKH patient.

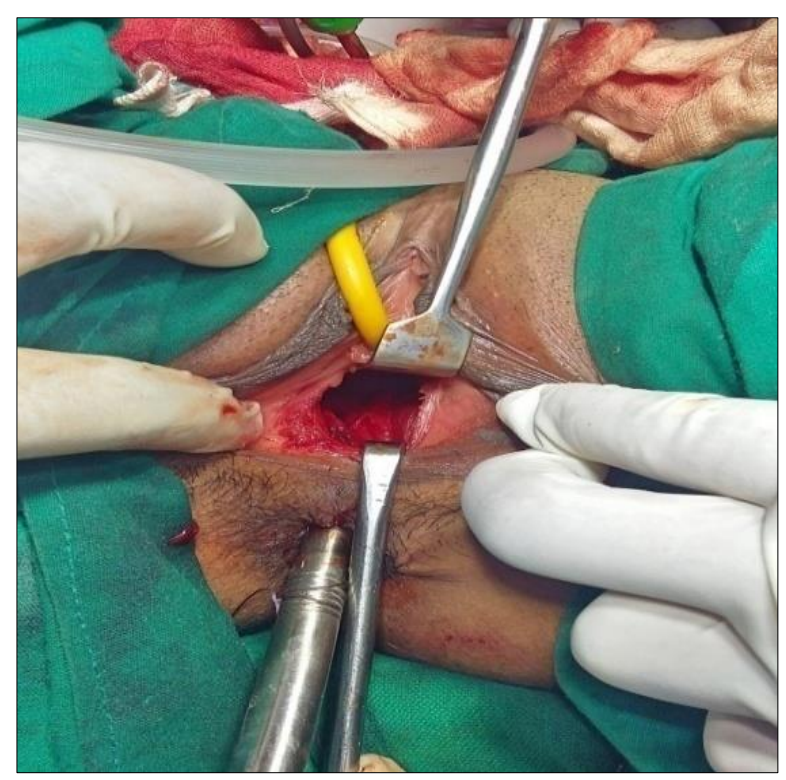

Figure 2: Vesicorectal space created.

The rudimentary vagina (Figure 1) was entered with a transverse incision and a vesicorectal space (nearly $10 \mathrm{~cm}$ deep and $4 \mathrm{~cm}$ wide) was created (Figure 2) between the bladder and urethra anteriorly and the rectum posteriorly just below the peritoneal sac, by sharp and at times blunt dissection. Meticulous hemostasis was observed during creating the neovaginal space and the space was examined for any injury to the adjacent organs.

Approximately $12 \times 8 \mathrm{~cm}$ split thickness skin graft was excised from inner aspect of the thigh with the help of Humby's knife. Dressing of the donor site was done 
aesthetically. A mould was prepared using soft sterile foam with a fenestrated Ryles tube no. 14 in the centre and doubly covered with condoms which were tightened at the distal end. This mould was then covered with an anti-septic paraffin impregnated gauze dressing (Bactigras). Then the graft was reverse sutured over the sponge mould with 3-0 monofilament absorbable suture material (Catgut 3-0).

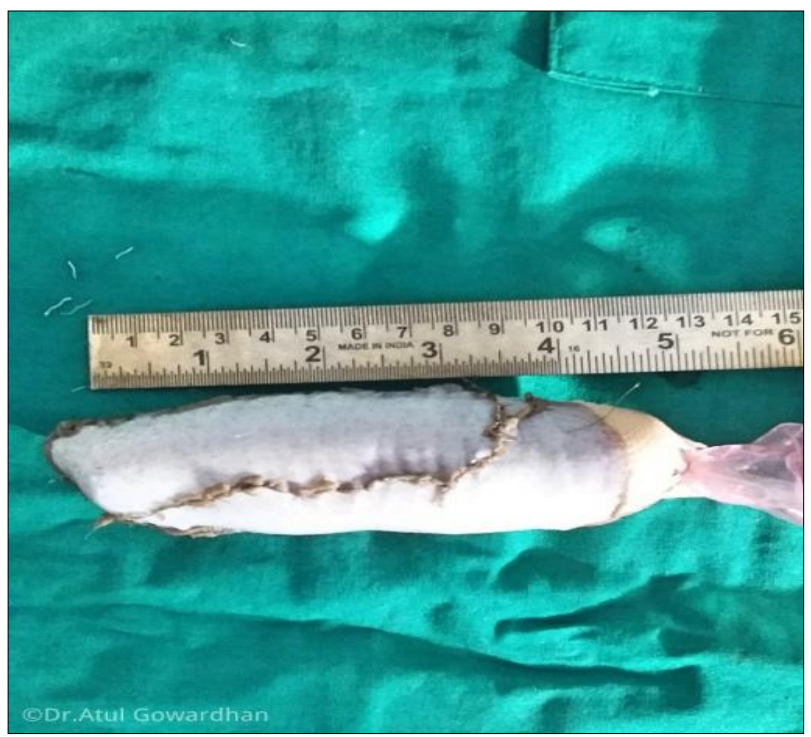

Figure 3: Prepared compressed mould with the reverse graft.

The sponge mould was then compressed by creating a negative suction with the suction machine through the Ryles tube and then the compressed mould (Figure 3) was placed into the neovaginal cavity created earlier. The negative pressure was then released so that the skin graft gets compressed against the walls of the neovagina. The labial folds were sutured over the mould by interrupted absorbable suture material so as to keep the mould steady. Tight dressing was applied.

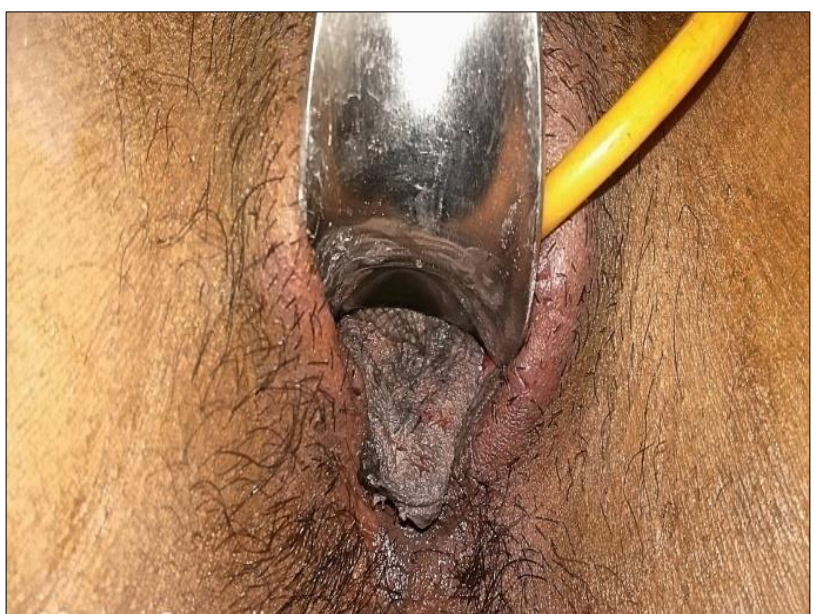

Figure 4: 90-100\% skin graft uptake on postoperative day 7.
Postoperatively prophylactic antibiotics were continued and patients were ambulated early to avoid postoperative complications. The vaginal mould was removed on the $7^{\text {th }}$ postoperative day and the cavity was cleaned with diluted iodine solution, graft uptake was observed (Figure 4) and second mould was again reinserted and the patients were discharged on the $10^{\text {th }}$ postoperative day. Patients were trained about the removal and reinsertion of the silicone penile mould. They were instructed to keep the mould in place constantly for the first 3 months with removal only during the time of vaginal irrigation, defecation and urination, followed by its use only in the night for the next 2-3 months. Sexual intercourse was allowed after 6 months. Initially lubricative jelly was asked to be used by the patients during sexual intercourse. Per speculum examination was done for all the patients during follow up visits for the graft complications, and the depth of the vagina created.

\section{RESULTS}

From 2014-2017, seven patients with MRKH syndrome with vaginal agenesis underwent modified McIndoe vaginoplasty in the department of obstetrics and gynecology at MGM Medical College and Hospital, Navi Mumbai. The patients were followed up nearly for 2 years post-surgery.

Mean duration of the surgery was 120 minutes (range, 100-150 minutes). No significant bleeding was seen during the procedure. Blood transfusion was not required and no major complication noted. Mean change in postoperative haemoglobin was $1.2 \pm 0.5 \mathrm{gm} / \mathrm{dl}$. Mean hospital stay was 10 days (range, 8-14 days).

Rehospitalisation or re-intervention was not observed. There were no issues with the donor site. No infection at the surgical site was noted during the early or delayed post-operative phase. Post-operative stricture or contracture or fistula formation was not reported in any patient. All the patients were satisfied with their neovaginal construction.

\section{Age distribution}

Patient's age varied from 18-34 years at the time of surgery with an average age of 22 years.

Table 1: Age distribution.

\begin{tabular}{|ll|}
\hline Age in years & No. of patients $(\mathbf{n}=7)$ \\
\hline $15-20$ & 2 \\
\hline $21-25$ & 3 \\
\hline $26-30$ & 1 \\
\hline $31-35$ & 1 \\
\hline
\end{tabular}

All the patients with MKRH syndrome who presented to us during the study period were included in the study as seen in Table 1. 


\section{Marital status}

Both married and about to married women were included in the study. The unmarried patients were about to get married in the duration of next 6-10 months (Table 2).

Table 2: Marital status.

\begin{tabular}{|ll|}
\hline Marital status & No. of patients $(n=7)$ \\
\hline Married & 3 \\
\hline Unmarried & 4 \\
\hline
\end{tabular}

\section{Preoperative depth of the vagina}

MRKH syndrome patients may have either blind vaginal pouch or lower $1 / 3$ of the vagina may be formed. All the patients were included in the study (Table 3 ).

Table 3: Preoperative depth of vagina.

\begin{tabular}{|c|c|}
\hline $\begin{array}{l}\text { Preoperative depth of the } \\
\text { vagina in } \mathrm{cm}\end{array}$ & No. of patients $(n=7)$ \\
\hline$<1$ & 3 \\
\hline $1-1.5$ & 3 \\
\hline $1.5-2$ & 1 \\
\hline
\end{tabular}

\section{Graft up takes}

The percentage of split thickness skin graft uptake was evaluated on seventh postoperative day after removing the initial mould. Sloughed off graft was trimmed and finally healing was noticed in subsequent visits by secondary intention.

Table 4: Percentage of graft uptake.

\begin{tabular}{|l|l|}
\hline Percentage of graft uptake & No. of patients $(\mathbf{n}=7)$ \\
\hline $90-100 \%$ & 3 \\
\hline $80-90 \%$ & 4 \\
\hline$<80 \%$ & 0 \\
\hline
\end{tabular}

\section{Post-operative depth of vagina}

Depth of the vagina achieved was measured 6 weeks after the surgery.

\section{Table 5: Post-operative depth of the vagina.}

\begin{tabular}{|l|l|}
\hline $\begin{array}{l}\text { Post operative depth of the } \\
\text { vagina in } \mathrm{cm}\end{array}$ & No. of patients $(\mathbf{n}=7)$ \\
\hline Up to $7 \mathrm{~cm}$ & 2 \\
\hline Up to $8 \mathrm{~cm}$ & 3 \\
\hline Up to $9 \mathrm{~cm}$ & 2 \\
\hline
\end{tabular}

\section{Postoperative width of the vagina}

Similarly, width of the vagina acquired was also assessed after 6 weeks of the procedure.
Table 6: Postoperative width of the vagina.

\begin{tabular}{|l|l|}
\hline $\begin{array}{l}\text { Postoperative width of } \\
\text { the vagina in } \mathrm{cm}\end{array}$ & No. of the patients $(\mathbf{n}=7)$ \\
\hline Up to $3 \mathrm{~cm}$ & 3 \\
\hline Up to $3.5 \mathrm{~cm}$ & 3 \\
\hline Up to $4 \mathrm{~cm}$ & 1 \\
\hline
\end{tabular}

Sexual gratification was decided on the individual patient's verdict about the contentment of the neovagina. This study did not use any justifiable questionnaires for the same.

\section{DISCUSSION}

The achievement of good results in neovaginal construction requires a technically expert surgical team and a surgical procedure that is simple, effective and associated with fewer complications, as it is always said that the original surgery is more likely to succeed than the repeat procedures.

Primarily, the surgical techniques for vaginoplasty included the flap method, bowel loop substitution and the skin graft techniques. Amongst these, modified McIndoe vaginoplasty has gained much popularity due to its clarity, efficacy and less morbidity, as described by Hojsgaard A et al. ${ }^{10}$ This was also reflected in this study as there were no complications noted and repeat interventions were not required.

As observed in this study, the mean operative time was 120 minutes (range, 100-150 minutes). This was comparable with a study done by Motta GL et al, where the mean surgery time was 121 minutes. $^{20}$ The mean operative time recorded in a study done by Klingele CJ et al, was 105 \pm 51 minutes (range, 20-269 minutes). ${ }^{21}$ Blood loss during the surgical procedure was not significant and blood transfusions were not needed in this study. This was also comparable with a study done by Motta GL et al. $^{20}$

This study assessed an average fall in the postoperative haemoglobin as $1.2 \pm 0.5 \mathrm{gm} / \mathrm{dl}$, where as it was $1.7 \pm 1.2$ $\mathrm{gm} / \mathrm{dl}$ in a study done by Klingele CJ et al in $2003 .{ }^{21}$ The average hospital stay noticed in this study was 10 days (range, 8-14 days) whereas the average hospital stay was $11 \pm 3.2$ days in a study done by Klingele CJ et al. ${ }^{21}$ The mean hospital stay was 8 days (range, 5-18 days) in a study done by Motta GL and 12 days (range, 8-17 days) in a study done by Buss and Lee..$^{20,22}$

The graft up take was more than $80 \%$ on $7^{\text {th }}$ postoperative day in this study (Table 4). Garcia and Jones described complete $(100 \%)$ graft uptake in $73 \%$ of the patients on 10th postoperative day and $80-90 \%$ graft uptake in another $20 \%$ of their patients. ${ }^{23} 80-90 \%$ of graft up take was also reported by a study done by Buss and Lee in their study. ${ }^{22}$ 
The average depth of the vagina achieved postoperatively in this study patients was $7-9 \mathrm{~cm}$ (Table 5). Similarly, the average length of the vagina measured 9.5 $\mathrm{cm}$ (range, $5-14 \mathrm{~cm}$ ) in a study done by Hojgaard and Villadsen. ${ }^{10}$ This study was also comparable with a study done by Chen et al where an average postoperative vaginal length of $8.8 \mathrm{~cm}$ (range, 7.8-9.6 cm) was observed. ${ }^{24}$ Motta GL et al noticed a mean postoperative vaginal depth of $11.3 \mathrm{~cm}$ (range, $10-13 \mathrm{~cm}$ ) in their study. ${ }^{20}$ The neovaginal depth ranged from 9.8 to $10.4 \mathrm{~cm}$ (average, $10.1 \mathrm{~cm}$ ) in a study done by Akin S. ${ }^{25}$

The mean diameter of the vagina observed postoperatively in this study patients was 3-4 cm (Table $6)$. This is comparable with a study done by Hojgaard and Villadsen where the average diameter of the vagina was $3.7 \mathrm{~cm}$ (range, $3-4 \mathrm{~cm}$ ). ${ }^{10}$ Similarly, the neovaginal width obtained in a study done by Akin S, was 4.4 to $5.2 \mathrm{~cm}$ (average, $4.8 \mathrm{~cm}$ ). ${ }^{25}$ Most of the studies on McIndoe vaginoplasty have stated the establishment of normal sexual activity after the procedure but none of these studies have used a valid survey on assessment of patient's sexual gratification. ${ }^{26,27}$ These studies based their results on the patient's verbal approval of sexual satisfaction by absence of pain and achievement of orgasm. Similar results were also observed in this study.

\section{CONCLUSION}

Authors conclude that the use of split thickness skin graft for vaginal reconstruction in patients with MRKH is safe and successful method with no occurrence of vaginal contraction or fore-shortening. This method has the following merits-

- It is a simple and straight forward procedure.

- Laparotomy and intestinal surgery are not required

- It is associated with very low morbidity and no mortality

- Perineal area is not disturbed and it designs a normal looking vagina

- The neovagina is accurate in its anatomical location and orientation

- The donor site is good aesthetically

- It guarantees acceptable sexual satisfaction.

However, a large-scale study is further required to evaluate the results of vaginal reconstruction for MRKH patients using the split thickness skin graft.

Funding: No funding sources Conflict of interest: None declared

Ethical approval: The study was approved by the Institutional Ethics Committee

\section{REFERENCES}

1. Goldwyn RM. History of attempts to form a vagina. Plast Reconstruct Surg. 1977;59:319.
2. Mayer CAJ. Uterus malformation and its types with remarks on parenchymal types and septums. J Chirurgie Augen-Heilkunde Berlin. 1829;13:525.

3. von Rokitansky KF. The malformations of the uterus. Medizinische Jahrbucher Kaiserl Konigl Osterreichischen Staates, Wien. 1838;26:39.

4. Kuster H. Uterine didelphus with rudimentary vagina. Zeitschrift Geburtshilfe Gyna Kologie, Stuttgart. 1910;67:692.

5. Hauser GA, Keller M, Koller T. The RokitanskyKuster syndrome: Uterine bicornus with rudimentary vagina. Gynaecol Basel. 1961;151:111.

6. Hauser GA, Schreiner WE. The Mayer-RokitanskyKuster syndrome. Schweizerische Medizinische Wochenschrift, Basel. 1961;91:383.

7. Capraro VJ, Gallego MB. Vaginal agenesis. Am J Obstet Gynecol. 1976;124:98-107.

8. Tolhurst DE, Helm TWJS van der. The treatment of vaginal atresia. Surg Gynecol Obstet. 1991;172:40714.

9. Counseller VS, Flor FS. Congenital absence of the vagina: further results of treatment and a new technique. Surg Clin North Am. 1957;37:1107-18.

10. Hojsgaard A, Villadsen I. McIndoe procedure for congenital vaginal agenesis: complications and results. Br J Plast Surg. 1995;48:97-102.

11. Laub DR, Laub DR. Mullerian and ectodermal vaginal agenesis. In: Smith JW, Aston SJ; eds. Plastic Surgery. Boston: Little, Brown and Co; 1991:1375-1392.

12. Bean EJ, Mazur T, Robinson AD. MayerRokitansky-Kuster-Hauser syndrome: sexuality, psychological effects, and quality of life. J Pediatr Adolesc Gynecol. 2009;22:339.

13. Evans TN, Poland ML, Boving RL. Vaginal malformations. Am J Obstet Gynecol. 1981;141:91020.

14. Mobus VJ, Kortenhorn K, Kreienberg R, Volker F. Long-term results after operative correction of vaginal aplasia. Am J Obstet Gynecol. 1996;175:617-24.

15. Williams JK, Lake M, Ingram JM. The bicycle seat stool in the treatment of vaginal agenesis and stenosis. J Obstet Gynecol Neonat Nurs. 1985; $14: 147-50$.

16. Hensle TW, Gjertson CK, Reiley EA. Vaginal reconstruction: a review. AUA Update Series. 2005;24:29.

17. Vesanovic S, Panajotovic L, Garalejic E. Sensibility of vagina reconstructed by McIndoe's method in Mayer-Rokitansky-Küster-Hauser syndrome. Vojnosanitetski Pregled. 2008;65(6):449-55.

18. McIndoe AH, Banister JB. An operation for the cure of congenital absence of the vagina. $\mathrm{Br} \mathrm{J}$ Obstet Gynaecol. 1938;45:490.

19. McIndoe A. The treatment of congenital absence and obliterative conditions of the vagina. Br J Plast Surg. 1950;2:254-67.

20. Motta GL, Tavares PM, Burttet LM, Berger M, Silva Neto B, Rosito TE. Vaginoplasty with full-thickness 
mesh skin graft for vaginal agenesis. Urol. 2016;98:200-3.

21. Klingele CJ, Gebhart JB, Croak AJ, DiMarco CS, Lesnick TG, Lee RA. McIndoe procedure for vaginal agenesis: long-term outcome and effect on quality of life. Am J Obstet Gynecol. 2003;189:1569-73.

22. Buss JG, Lee RA. McIndoe procedure for vaginal agenesis: results and complications. Mayo Clinic Proceed.1989;64:758-61.

23. Garcia J, Jones HW. The split thickness graft technic for vaginal agenesis. Obstet Gynecol. 1977;49:32832.

24. Chen YB, Cheng TJ, Lin HH, Yang YS. Spatial W. Plasty full-thickness skin graft for neovaginal reconstruction. Plast Recons Surg. 1994;94:727-31.

25. Akn S. Experience with neovaginal construction using the full-thickness skin graft in vaginal agenesis. Ann Plast Surg. 2004;52:391-6.
26. Borkowski A, Czaplicki M, Dobronski P. Twenty years of experience with Krzeski's cystovaginoplasty for vaginal agenesis in Mayer-RokitanskyKüsterHauser syndrome: Anatomical, histological, cytological and functional results. BJU Inter. 2008;101:1433-40.

27. Rock JA, Reeves LA, Retto H, Baramki TA, Zacur HA, Jones HW. Success following vaginal creation for mullerian agenesis. Fertil Steril. 1983;39:809-13.

Cite this article as: Gowardhan AK, Bagade PM. A clinical study of modified McIndoe vaginoplasty with split thickness skin graft: a tertiary care experience. Int J Reprod Contracept Obstet Gynecol 2020;9:2692-7. 